andere Lleine Wunde mit gerissenem Rande und da beginnend ein circa $\frac{1}{2}$ Centimeter breites Erythem, das sich wie Hautgefässe verästelnd und hier und da auslaufend bis an die rechte Brustwarze und bis unter den rechten Arm reichte, und in der Zeichnung die grösste Aehnlichkeit mit der für Gebirge auf Landkarten üblichen hatte; dasselbe war bei der Berührung schmerzhaft aber olne deutlich wahrnehmbare Anschwellung.

Die ganze rechte Seite des Halses war geschwollen, steif und sehr schmerzhaft. Dabei heftige Schlingbeschwerden, aber die Functionen der Augen nicht alterirt.

An den Haaren und Kleidern fand sich Keine Spur von Verbrennung.

Nach ungefähr 8 Tagen waren die rothen Zeichnungen am Halse ohne bemerkbare Abschuppung oder gar Schorfbildung verschwunden.

Bei dem 22 Jahre alten Mädchen des Hrn. B. ans B, fand ich auf dem rechten Scheitelbein eine vielleicht zolllange Wunde mit scharfem Rande ohne Verbrennung der Haare und ausserdem fast ganz dieselbe baumförmiger GefässverästeInng ähnliche Zeichnung auf der rechten Seite des Halses, wie bei dem andern Mädchen und eben solche an beiden Unterschenkeln und Füssen ohne Continuität untereinander.

Auch in diesem Fall keine Spur ron Verbrennung an den Kleidungsstücken.

Bemerken will ich hierzu, dass ich, da andere Zeichen von Verbrennung fehlten, auch die bellrothen aderartigen Zeichnungen nicht für oberflächliche Verbrennungen balten kann; viel wahrscheinlicher erscheint es mir, dass der Blitzschlag, vielleicht den Gefässverzweigungen folgend, Erythem oder ganz Jeichte Hautentzündung hervorgerufen batte.

Fernere Beobachtungen werden darüber entscheiden.

6.

\title{
Secundäre Cancroidinfiltration des Nervus mentalis bei einem Fall von Lippencancroid.
}

\author{
Von Dr. E. Neumann in Königsberg i. Pr.
}

In No. 46. der Allg. Medicin. Centralzeitung vom 8. Juni d. J. befindet sich der Bericht über eine Sitzung der Niederrbeinischen Gesellschaft für Natur-und Heilkunde, in welchem einer Mittheilung des Hrn. Prof. Busch über einen Fall von Cancroid der Unterlippe erwähnt ist, bei wclehem die Neubildung sich auf die beiden Nervi mentales fortgepfanzt und dieselben zu harten rundlichen Strängen, die durch die Lippe hindurch deutlich fühlbar waren, umgewandelt hatte. Busch bemerkte, früher eine gleiche Erkrankung nicht gesehen zu haben. Es möge daher der Seltenbeit wegen bier, ein ganz correspondirender Fall eine Stelle 
finden, welchen ich, noch ehe jene Notiz zu meiner Kenntwiss gelangt, im Juli d. J. für Herrn Medicinalrath Wagner zu untersuchen Gelegenheit hatte.

Dem mir gütigst mitgetheilten klinischen Journal entnehme ich folgende Angaben: Bei eimem 45jährigen Landmanne zeigte sich eine die Mitte der Unterlippe einnehmende wallnussgrosse Geschwulst, die vom Lippensaume bis zur Grube über dem Kinn sich erstreckte und jederseits etwa das äussere Viertel der lippe intact liess. Die Oberfläche ist zerfallen und bildet ein kraterförmiges Geschwür mit wallartig aufgeworfenen, harten, knotigen Rändern. Druck auf die Geschwulst ist wenig empfindlicl, doch zieht sich vom untern Geschwulstrande nach links hin ein dünner, härtlicher, bei Berührung seh r s chmerz h after Strang von etwa $1 \frac{1}{2}$ Zoll Länge bis zur Unschlagsstelle der Scbleimhaut auf den Knochen, wo es fraglich war, ob or sich in diesen hineinerstreckte. Spontane Schmerzen hat Patient in der seit Jabren erkrankten Lippe in irgend erheblichem Grade nicht gehabt. Bei der Operation liess sich der Strang aus den Weichtheilen leicht herausschälen, ohne einen Zusammenhang mit dem knochen zu zeigen.

Die anatomische Untersuchung ergab in der Geschwalst nichts irgend Ungewöhnliches, die cancroide Infiltration war bis tief in die Muskelsubstanz des Orbicularis eingedrungen, ihre Grenze durch eine sclwach wellenförmige, scharfe Linie gezeichnet. Mikroskopisch betrachtet bildeten die bekannten concentrisch geschichteten Epidermiskngeln den Hauptbestondtheil, dazwischen befand sich ein spärlicher Rest schmaler mit wuchernden Bindegewebskörpern durchsetzter Bindegewebszüge. Der erwähnte Strang zeigte sich etwas über 1 Linie dick, derb, etwas ungleichmässig knotig aufgetrieben, von weisser Farbe. Er war Jose in ganz normales Muskelgewebe eingebettet. In die Geschwulst hinein konnte er nicht verfolgt werden. Es liess sich leicht constatiren, dass er durch einen degenerirten Nerven gebildet wurde, welcher der Lage nacli kejn anderer als der linke Nervus mentalis sein konnte. Seine Faserbündel waren durch dieselben epidermoidalen Zellennester, wie sie sich in der Lippe selbst fanden, auseinander geworfen; ihre Entwicklung aus den Bindegewebskörpern des Perineurium und des Neurilemma war bequem zu verfolgen. Die Nervenfasern selhst schienen mir normal zu sein. Im Vergleich zu Busch's Fall wäre nur die einseitige Erkrankung in unserer Beobachtung bervorzubeben, während dort beide Nerven in gleicher Weise symmetrisch afficirt waren.

7.

\title{
Die Eiterbildung aul' Schleim - nnd serõsen Iänten.
}

\author{
Von Dr. E. Neumann in Königsberg i. Pr.
}

In einer im Sommer 1859 bei meiner Habilitation der hiesigen medicinischen Facultät vorgelegten, Ostern 1860 in den Königsberger Medicinischen Jalurbüchem (Bd. II. Heft 2) abgedruckten Ahhandlung "Ueber die Bildung des Eiters" hatte 